\title{
COLOMBIE
}

\section{AGCESSION A LA CONVENTION DE GENÈVE}

Berne, le 27 janvier 1908.

Au Comité international de la Croix-Rouge,

Genève.

\section{Messieurs,}

Nous l'avons l'honneur de vous informer qu'en date du 28 octobre 1907, la Légation de Colombie a notifié au Conseil fédéral l'adhésion de la République de Colombie à la Convention du 6 juillet 1906 pour l'amélioration du sort des blessés et malades dans les armées en campagne.

Veuillez agréer, Messieurs, l'assurance de notre considération distinguée.

Département politique fédéral, Brenner.

\section{ESPAGNE}

NOUVELLES DE LA SOGIÉTÉ ESPAGNOLE

Réorganisation de la Croix-Rouge espagnole.

Le Comité central madrilène, dans son bulletin de novembre et décembre 1907, annonce que la réorganisation de la Croix-Rouge sur les bases de $1899^{1}$ s'effectue dans toute l'Espagne, sans aucune difficulté, comme il l'espérait du reste, étant donné l'esprit d'abnégation qui distingue les sociétaires et l'enthousiasme qui les

1 Voy. T. XXX, p. 224. 